\title{
Pharmacology Curriculum and Teaching Methods: A Comparative Study Between Two Nursing Programs in A Nepalese College
}

\author{
Manoj Sharma and Kumud Kumar Kafle
}

Department of Pharmacology, Nepalese Army Institute of Health Sciences, Kathmandu, Nepal.

ABSTRACT
Introduction: Pharmacology is one of the basic science subjects included in graduate nursing programs
(B. Sc Nursing and Bachelor of Science in Nursing) under Tribhuvan University. Both these programs
are being run at our institute. This article describes the evaluation of pharmacology course and teaching
methodology at our institute by B. Sc Nursing (B. Sc) and Bachelor of Science in Nursing (BNS)
students and also compares students' views between these two nursing programs to facilitate
pedagogical learning.
Methods: At the end of the course of $2071-2072$ BS academic year of first year nursing students of B.
Sc and BNS programs, a structured teaching evaluation questionnaire was designed to obtain students'
view on pharmacology curriculum and lectures. Yates corrected Chi square test was applied whenever
necessary and p value considered significant at less than or equal to 0.05 .
Results: Only $37 \%$ B. Sc and $60 \%$ BNS students responded that the lecture content was in accordance
with the curriculum. Only $52 \%$ BNS and $97 \%$ B. Sc students found the course content to be relevant
and useful. $68 \%$ BNS students responded that they have felt a lot improvement in their understanding
of pharmacology subject as compared to just $23 \%$ of B. Sc students. Majority of the students preferred
the LCD mode of presentation.
Conclusion: There were minor differences found between opinions of two sets of students. Major need
for improvement areas suggested in curriculum were course content not being clear and the objectives
being ill defined. Similarly, in relation to facilitator, they have recommended to improve voice clarity.
Keywords: critical appraisal; feedback; nursing education

\section{INTRODUCTION}

Nepalese Army Institute of Health Sciences (NAIHS) is an institute affiliated to Tribhuvan University (TU) which runs two nursing programs in the bachelor level viz. Bachelor of Science in Nursing (B. Sc) and Bachelor in Nursing Sciences (BNS). TU introduced a three-year BNS program since 2070-2071 BS academic calendar (earlier it used to be a two-year course only) and included basic science subjects as part of its curriculum whereas basic science subjects were already a part of B. Sc Nursing program. Pharmacology is included as one of the basic science subjects in both

This work is licensed under: http:// creativecommons.org/licenses/by-nc-nd/4.0/

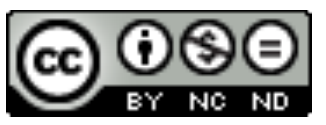

these programs in the first year of the course. B. Sc has a total credit of 70 hours whereas BNS has only 56 hours in pharmacology.

Students' feedback is an effective medium to evaluate an individual for the purpose of selfawareness and understanding. ${ }^{1}$ Effective feedback being nonjudgmental is an integral part of medical and nursing education in helping the teachers, students, mentors and instructors to know their weaknesses and reach their maximum potential. Feedback helps in correcting mistakes, reinforcing good performances and incorporating students' 
view in teaching methodology. Students' views are indispensable to correct teacher's misperception about his/her didactic methods which, if incorporated in pedagogic practices, may lead to effective teaching and learning exercises. ${ }^{2-4}$ For instance, many medical and nursing colleges include lectures, tutorials, practical classes; problem based learning and occasionally small group teaching and case discussions as the teaching methodology. So obtaining students' critical appraisal on the pharmacology lectures may be a good source for the improvement of the teaching methodology. ${ }^{4-6}$

Curricula in both the above mentioned nursing programs are integrated and the lectures are taken accordingly. Teaching evaluation of pharmacology courses, from students' learning to effectiveness of the curriculum and instructor, becomes important to have the efficient pharmacological classes. ${ }^{1}$ In addition, Pharmacology as a part of the various programs of health care education is of increasing importance for several reasons. This article describes the evaluation by B. Sc and BNS students on pharmacology course and teaching methodology at NAIHS and also compares students' views between these two nursing programs to facilitate pedagogical learning.

\section{METHODS}

A structured teaching evaluation questionnaire was designed to obtain students' view on Pharmacology curriculum and lectures at the end of the course during first year of B. Sc and BNS programs of 2071-2072 BS academic year. Among 30 students enrolled in B. Sc program and 27 students in BNS, all students of B. Sc and 25 students of BNS participated in the study. Institutional ethical clearance and students' verbal consent was taken.

The questionnaire contained 10 close-ended items that evaluated teaching effectiveness and 6 closeended items that evaluated the pharmacology curriculum/ course. One open-ended question was also incorporated to collect students' open comments on pharmacology course. Questionnaire forms where blinded.

Yates corrected Chi square test was applied as test of significance wherever applicable by using Epi Info Version 6 and level of significance ( $p$ value) was set at or less than $5 \%$.
Table 1: Responses on evaluation of Pharmacology curriculum/course in $\%$

\begin{tabular}{|c|c|c|}
\hline $\begin{array}{l}\text { Are the objectives well defined in } \\
\text { the curriculum? }\end{array}$ & B. Sc & BNS \\
\hline Well defined & 17 & 12 \\
\hline Partially defined & 37 & 64 \\
\hline Ill defined & 43 & 24 \\
\hline No comments & 3 & -- \\
\hline $\begin{array}{l}\text { Is the course content defined in } \\
\text { the curriculum? }\end{array}$ & B. Sc & BNS \\
\hline Yes, well defined & 7 & 28 \\
\hline Partially defined & 56 & 52 \\
\hline No, not defined & 37 & 16 \\
\hline No comments & -- & 4 \\
\hline $\begin{array}{l}\text { Is the lecture content in } \\
\text { accordance with the curriculum? }\end{array}$ & B. Sc & BNS \\
\hline Yes & 37 & 60 \\
\hline Partially & 26 & 28 \\
\hline No & 7 & 8 \\
\hline No comments & 30 & 4 \\
\hline Coverage & B. Sc & BNS \\
\hline Extensive & 3 & 24 \\
\hline Adequate & 73 & 64 \\
\hline Inadequate & 23 & 12 \\
\hline No comments & -- & -- \\
\hline Total no. of lecture hours & B. Sc & BNS \\
\hline Too many & 7 & -- \\
\hline Adequate & 46 & 56 \\
\hline Inadequate & 46 & 44 \\
\hline No comments & -- & -- \\
\hline Relevance & B. Sc & BNS \\
\hline Very useful & 3 & 44 \\
\hline Useful & 97 & 52 \\
\hline Not useful & -- & -- \\
\hline No comments & -- & 4 \\
\hline
\end{tabular}


Original Article Evaluation of Pharmacology Curriculum and Teaching; Sharma M et al.

Table 2: Responses of students on evaluation of teaching effectiveness in percentage.

\begin{tabular}{|c|c|c|}
\hline Students Participation & B. Sc & BNS \\
\hline Adequate & 33 & 40 \\
\hline Inadequate & 60 & 60 \\
\hline Not at all & 7 & -- \\
\hline No comments & -- & -- \\
\hline Questions by students & B. Sc & BNS \\
\hline Encouraged & 53 & 40 \\
\hline Partially encouraged & 37 & 60 \\
\hline Discouraged & 7 & -- \\
\hline No comments & 3 & -- \\
\hline $\begin{array}{l}\text { Mode of presentation you } \\
\text { prefer }\end{array}$ & B. Sc & BNS \\
\hline LCD slides & 93 & 80 \\
\hline White board/marker & 3 & 20 \\
\hline Verbal & 3 & -- \\
\hline No comments & -- & -- \\
\hline $\begin{array}{l}\text { Improvement in your } \\
\text { understanding of } \\
\text { Pharmacology subject }\end{array}$ & B. Sc & BNS \\
\hline A lot & 23 & 68 \\
\hline To some extent & 77 & 24 \\
\hline Not at all & -- & 4 \\
\hline No comments & -- & 4 \\
\hline
\end{tabular}

\section{RESULTS}

Table 1 shows the responses of the students on pharmacology curriculum/ course. Majority of the students in both the programs said that the objectives and the course content are partially defined in the curriculum. Only $37 \%$ B. Sc and $60 \%$ BNS students responded that the lecture content was in accordance with the curriculum and the difference was found to be significant ( $p$ $=0.016$ ). Only $52 \%$ BNS students found the relevance of the course to their profession to be useful as compared to $97 \%$ B. Sc students. Course coverage was found to be adequate by majority of the students, but interestingly, 24\% BNS students found the coverage to be extensive.
Table 3: Evaluation of teaching effectiveness of facilitator by students' in percentage.

\begin{tabular}{|c|c|c|}
\hline Presentation & B. Sc & BNS \\
\hline Good & 73 & 84 \\
\hline Partially organized & 27 & 16 \\
\hline Disorganized & -- & -- \\
\hline No comments & -- & -- \\
\hline $\begin{array}{l}\text { Use of white board / } \\
\text { LCD slides }\end{array}$ & B. Sc & BNS \\
\hline Good & 63 & 88 \\
\hline Fair & 33 & 12 \\
\hline Poor & 3 & -- \\
\hline No comments & -- & -- \\
\hline Clarity of LCD slides & B. Sc & BNS \\
\hline Good & 53 & $92(p=0.0304)$ \\
\hline Fair & 40 & $4 \%$ \\
\hline Poor & 7 & -- \\
\hline No comments & -- & 4 \\
\hline Pace & B. Sc & BNS \\
\hline Too rapid & 27 & 36 \\
\hline About right & 70 & 48 \\
\hline Too slow & -- & -- \\
\hline No comments & 3 & 16 \\
\hline Voice clarity & B. Sc & BNS \\
\hline Good & 47 & $92(p=0.0005)$ \\
\hline Fair & 43 & 8 \\
\hline Poor & 10 & -- \\
\hline No comments & -- & -- \\
\hline Audibility & B. Sc & BNS \\
\hline Good & 47 & $88(\mathrm{p}=0.0188)$ \\
\hline Fair & 43 & 8 \\
\hline Poor & 10 & -- \\
\hline No comments & -- & 4 \\
\hline
\end{tabular}


Table 2 shows the responses on evaluation of teaching effectiveness in relation to the students.

Sixty percent students in each of the programs have responded that the students' participation in class interactions is inadequate; however, most of them feel that the questions by students were encouraged. Sixty eight percent BNS students had felt a lot improvement in their understanding of pharmacology subject as compared to just $23 \%$ of B. Sc, however, the difference was not statistically significant. Eighty percent BNS and $93 \%$ B. Sc students responded that they prefer LCD mode of presentation as compared to other modes.

As shown in table 3, most of the students felt that the presentation and use of teaching aids viz. LCD slides/ white board was good. Thirty six percent BNS students said the pace was too rapid whereas $70 \%$ B. Sc students felt it was about right. Fifty three percent B. Sc and $92 \%$ BNS students found the clarity of LCD slides to be good and the difference was significant. There is also a significant difference in response to voice clarity and audibility.

\section{Responses to the open ended question:}

\section{BNS students}

- The curriculum is overloaded and objectives not clear (5)

- It's difficult to cope with all the basic science subjects along with the nursing subjects in a single year (3)

- It would be better if the total pharmacology classes were divided in every year (6)

- Applied aspects like drug preparations and administration should also be discussed and irrelevant topics should be excluded (6)

\section{B. Sc students}

- Teachers have put really good effort in making us understanding this new subject (4)

- Teaching pharmacology will make it practically very useful in the use of drugs in future (5)

- Pharmacology is very vast, so it would be better if the whole curriculum is divided in two years and taught in first and second year (10)

- Class tests and monthly tests are required (3)

- Teaching more in less time has made it very difficult for us to understand (15)

- Pharmacology is very difficult to memorize (4)

\section{DISCUSSION}

This study shows that the students' views on facilitator's way of presentation, use and clarity of teaching aids, and pace was acceptable but there is room for improvement with regard to clarity of voice and audibility and provides a feedback to the presenter to be loud and clear. This could be due to personal limitations of the facilitator as well as technical glitches like the adjustments of a microphone. Overall the students' response on the quality of teaching was similar with minor differences only (Table 3 ).

Mixed responses on view of students' participation and interactions during lectures were obtained. Students from both the programs felt that their participation in interaction is inadequate and majority of the BNS students have responded that the questions by students were partially encouraged (table 2). The students have preferred the use of LCD slides as teaching aid compared to other methods of presentation. This could possibly be due to the reason that pictorial descriptions can be done better using LCD slides and the facilitator will be facing more towards the students using this method which perhaps increases the teaching effectiveness. For any system of education to function smoothly, it is said that it should be acceptable to both the receiver and the provider and this holds true for medical and nursing education as well ${ }^{4}$. It is important before advocating any changes that the students' perception to the existing system is obtained. Obtaining a feedback from the students is one of the ways to assess the relevance of the innovations and modifications and also to find out if the objectives were correct and understandable by the students. ${ }^{8-10}$ Moreover, this study suggests that it is a challenging job on teacher's part to increase the knowledge level of the students as there is a variation in relation to their understanding of pharmacology subject (Table 2).

Majority of the students responded to the open ended question by expressing their views in the favor of dividing the total pharmacology classes for more than one year instead of teaching the whole course in first year only as it would be difficult for them to understand the subject better. This suggests that students are very much interested in and aware of the importance of pharmacology as nursing students are dealing with drugs and their preparations in their profession. Additionally, students' level of satisfaction is low as far as existing depth and extent of pharmacology taught to them is concerned. More regular class tests are necessary from the students' perspective so are 
explanations of the subject matter with the clinical and nursing correlation. This view of the students is in concordance with the study which showed that it is the quality and effectiveness of instructor and instruction which is associated with students' satisfaction. ${ }^{11}$

Limitations of this study include small sample size and failure to take into consideration the educators' and students' attitudes, intelligence levels, feelings, perception and experiences.

\section{CONCLUSION}

There were minor differences found between opinions of two sets of students. However, they have pointed some lacunae in curriculum like the course content not being clear and the objectives being ill defined. Similarly, in relation to facilitator, they have recommended to improve in voice clarity. More class interactions between the students and facilitators need to be employed along with more frequent assessments on the subject to keep up students' expectation.

\section{ACKNOWLEDGEMENT}

We express our sincere thanks to Dr Anjan Khadka and Mr Prakash Limbu of NAIHS for their help with data analysis.

\section{REFERENCES}

1. Paudel KR. Evaluation of Pharmacology didactic lectures for graduating Nursing students: A questionnaire based comparative study between two colleges in Nepal. Asian J Med Sci. 2011;2:159-63.

2. Rotem A, Craig P, Cox K. In search of criteria for assessment of medical education. Med Edu. 1981;15:85-91. DOI: https://doi.org/10.1111/j. 1365-2923.1981.tb02402.x

3. Tofocic SP, Branch RA, Jackson EK, Cressman MD, Kost CJ. Teaching Clinical Pharmacology and therapeutics: selective for fourth year medical students. J Clin Pharmacol. 1998;38:670-9. DOI: https://doi.org/ 10.1002/j.1552-4604.1998.tb04805.x

4. Ginns P, Barrie S. Developing and testing studentfocused teaching evaluation survey for university instructors. Psychological Reports. 2009;104:1019-32. DOI: https://doi.org/10.2466/PR0.104.3.1019-1032

5. Das BP, Sethi A, Rauniar GP, Sangraula H. Students' critical appraisal on the evaluation of analgesics in laboratory animals versus simulated clinical trial. Nepal Med Coll J. 2006;8(4):234-7.

6. Bata-Jones B, Avery MD. Teaching pharmacology to graduate nursing students: evaluation and comparison of web based and face-to-face methods. J Nurs Educ. 2004;43:185-9.
7. Ryan M, Carlton KH, Ali NS. Evaluation of traditional classroom teaching methods versus course delivery via the World Wide Web. J Nurs Educ. 1999;38:272-7.

8. Tavares MA, Amandio JV, Cunha NT, Machado JD, Cardoso V, Silva MC. Evaluation of Practical sessions in clinical anatomy: a strategy for educational improvement. Clin Anat. 2002;15:51-5. DOI: https:// doi.org/10.1002/ca.1092

9. Dornan T, Brown M, Powley D, Hopkins M. A technol-ogy using feedback to manage experience based learning. Med Teacher. 2004;26:736-8. DOI: https:// doi.org/10.1080/01421590400016340

10. Paudel KR, Sharma M. Pharmacology curriculum and career options in dental and basic medical sciences: Graduating dental students' perspective under Kathmandu University in Nepal. Asian J Med Sci. 2014;5(2):106-12.

11. Debourgh GA. Predictors of student satisfaction in distance-delivered graduate nursing courses: what matters most? J Prof Nurs. 2003;19(3):149-63. DOI: https://doi.org/10.1016/S8755-7223(03)00072-3

12. Merisotis JP, Phipps RA. What's the difference? Outcomes of distance vs. traditional classroom-based learning. Change. 1999;31(3):12-7. DOI: https://doi.org/ $10.1080 / 00091389909602685$ 